\title{
Adhesion to Extracellular Matrix Proteins can Differentiate between Human Bone Marrow Derived Mesenchymal Stem Cells and Fibroblasts
}

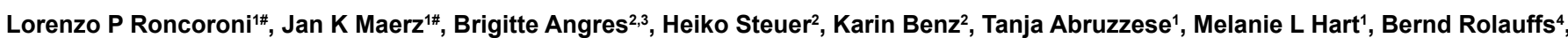
Gerd Klein $^{5}$, Dieter Stoll ${ }^{6}$ and Wilhelm K Aicher ${ }^{1 *}$

${ }^{1}$ Department of Urology, University of Tuebingen Hospital, Tuebingen, Germany

${ }^{2}$ Natural and Medical Sciences Institute at the University of Tuebingen (NMI) Reutlingen, Germany

${ }^{3}$ Cellendes $\mathrm{GmbH}$, Reutlingen, Germany

${ }^{4}$ Department of Traumatology, BGU Hospital, Tuebingen, Germany

${ }^{5}$ Department of Internal Medicine II, University of Tuebingen Hospital, Tuebingen, Germany

${ }^{6}$ FB3 Life Sciences, University of Applied Sciences, Sigmaringen, Germany

\#Lorenzo P Roncoroni and Jan K Maerz contributed equally to this study and therefore share first authorship

\begin{abstract}
Mesenchymal stem or stromal cells (MSC) contribute in vivo to wound repair, and can be utilized for tissue regeneration. In contrast, fibroblasts may contribute to scar formation, and may even hamper functional regeneration. Depending on the clinical application, MSC are sometimes attached to a scaffold to maintain the cells in the area of regeneration. We, therefore, screened for proteins that allow a preferential binding of MSC, and avoid strong adherence of fibroblasts. The human MSC were isolated from bone marrow (bmMSC), or term placenta (pMSC). Synovial fibroblasts (SF) and dermal fibroblasts (DF) served as controls. In the first set of experiments, binding of bmMSC and SF to extracellular matrix (ECM) proteins was investigated by multiple substrate array $\left(\mathrm{MSA}^{\circledR}\right)$. From $\mathrm{MSA}^{\otimes}$ protein analyses, 57 peptides with potential MSC-binding sites were selected, and the binding of the cells to these peptides was determined. We report that MSC differ from fibroblasts in their binding to proteins of the extracellular matrix. MSC bind with higher efficiency to laminin-111, collagens-I, -III, and -IV and tenascin-C compared to fibroblasts, while both cell types bind with high efficiency to fibronectin, vitronectin and laminin-511. We conclude that overall MSC seem less selective, with respect to binding extracellular matrix components compared to fibroblasts, and fibroblasts attach to fewer proteins and peptides.
\end{abstract}

Keywords: Mesenchymal stem cells; Bone marrow; Extracellular matrix proteins; Fibroblasts

Abbreviations: bmMSC: Bone marrow derived MSC; DF: Dermal Fibroblast; ECM: Extracellular Matrix; FN: Fibronectin; LM: Laminin; MSA $^{\circledR}$ : Multiple Substrate Array; MSC: Mesenchymal Stem or Stromal Cell; NC: Nitro Cellulose; PLL: Poly L-lysine; pMSC: Placenta derived MSC; SF: Synovial Fibroblast; TGF: Transforming Growth Factor

\section{Introduction}

Mesenchymal stromal cells (MSC) are multipotent progenitor cells that reside in different tissues [1-5]. Initially, MSC were isolated from bone marrow [6], and bone marrow until now remains the main source for MSC, for both diagnostic and clinical applications [3,7-10]. However, recent studies indicate that MSC from different sources, such as bone marrow, adipose tissue, umbilical cord or term placenta differ in their expression of cell surface markers [11]. Moreover, within the bulk MSC population of a given source, subsets may be identified and enriched by aid of antibodies [12-15]. These studies suggest that MSC from different sources might use distinct sets of receptors to facilitate homing or adhesion of MSC, to and in a given microenvironment. In our previous studies, we observed that bmMSC express the $\alpha 1-, \alpha 2-, \alpha 3-$, a6-, $\alpha 7-, \alpha 9-, \alpha 11-$, and $\beta 1$-chains of integrins, and TGF- $\beta 1$ regulated the expression of $\alpha 2 \beta 1$ integrin, thus facilitating the attachment of MSC to extracellular matrix proteins [16]. We hypothesized that fibroblasts might, therefore, differ from MSC in their expression of matrixbinding receptors, and investigated the binding of MSC to different proteins and peptides, in comparison to the binding of fibroblasts in more detail.

\section{Materials and Methods}

\section{Isolation of cells}

The MSC were isolated from bone marrow (bmMSC, 12 donors), or human term placenta (pMSC, 5 donors), after written consent and expanded, as described recently [16,17]. Human synovial fibroblasts (SF, 4 donors), or human dermal fibroblasts (DF, 6 donors), were isolated from surgical waste and expanded, as described recently $[18,19]$. All MSC preparations were characterized for adherent growth of the cells with fibroblastoid appearance, for expression of the relevant inclusion and exclusion markers (CD73, CD90, CD105, CD11b or CD14, CD34, CD45), by flow cytometry, and their tri-lineage differentiation capacity, as suggested by the International Society for Cellular Therapy (ISCT) consensus conference [20], and as described recently [16,17,21]. The study was approved by the Ethics Committee of the Medical Faculty of University of Tuebingen.

\section{Multiple Substrate Array (MSA ${ }^{\circledR}$ )}

To investigate the binding of the MSC to extracellular matrix proteins, a $\mathrm{MSA}^{\circledR}$ screening for MSC adhesion was performed [22]. In brief, $0.2 \mu \mathrm{L}$ drops of protein solutions containing type I-, III, IV-, V- and VI- collagens, fibronectin, laminin-111, laminin-511,

*Corresponding author: Wilhelm K Aicher, PhD, Department of Urology University of Tuebingen Hospital, 72076 Tuebingen, Germany, Tel.: +49 7071298 7020; Fax: +49 7071292 5072; E-mail: aicher@uni-tuebingen.de

Received February 26, 2013; Accepted March 26, 2013; Published March 28 2013

Citation: Roncoroni LP, Maerz JK, Angres B, Steuer H, Benz K et al. (2013) Adhesion to Extracellular Matrix Proteins can Differentiate between Human Bone Marrow Derived Mesenchymal Stem Cells and Fibroblasts. J Tissue Sci Eng S11: 008. doi:10.4172/2157-7552.S11-008

Copyright: @ 2013 Roncoroni LP, et al. This is an open-access article distributed under the terms of the Creative Commons Attribution License, which permits unrestricted use, distribution, and reproduction in any medium, provided the original author and source are credited. 
Citation: Roncoroni LP, Maerz JK, Angres B, Steuer H, Benz K, et al. (2013) Adhesion to Extracellular Matrix Proteins can Differentiate between Human Bone Marrow Derived Mesenchymal Stem Cells and Fibroblasts. J Tissue Sci Eng S11: 008. doi:10.4172/2157-7552.S11-008

Page 2 of 6

tenascin-C or vitronectin, at optimized concentrations, were printed on nitrocellulose (NC)-coated glass slides in $8 \times 8$ arrays using a Packard BioChip Arrayer ${ }^{\mathrm{m}}$, and air-dried (Figure 1A). The remaining surface area was sealed by covering the NC with StabilGuard ${ }^{\circledR}$ (SurModics, Eden Prairie, MN, USA) solution for $60 \mathrm{~min}$ at ambient temperature. A silicon frame was added on top of the arrays, to generate small cell culture chambers (Figure 1B). Then, $2 \times 10^{4}$ cells were added for $4 \mathrm{~h}$ to each array chamber and incubated on a rocking platform, placed in a humidified cell culture incubator with controlled atmosphere $\left(37^{\circ} \mathrm{C}\right.$, $10 \% \mathrm{CO}_{2}$ ). During this period of time, cells were allowed to bind to the proteins (Figure 1B). Then, the floating cells were rinsed off by PBS. The adherent cells were stained by Coomassie Brilliant Blue (SIGMAAldrich; Figure 1C), and counted by an automated microscope-based device (Leica IRDB, with a motorized sample sled). On each array, quadruplicates spots coated with poly-L-lysine (PLL), or BSA served as positive and negative controls, respectively [22]. The results are presented as the normalized number of cells per spot (mean \pm standard deviation), of three individual arrays per protein and cell type. Cells per spot counted on PLL were set as $100 \%$ (=positive control), and cells per spot counted on BSA as $0 \%$ (=negative control; Figure 1D). This kind of array investigates the avidity of the cell-matrix interaction since multiple binding sites on the ligands may interact with multiple receptors. For this type of cell-matrix interaction, we coin the term "binding" in this article. From proteins binding MSC with high avidity, candidate peptides for further analysis were delineated in silico.

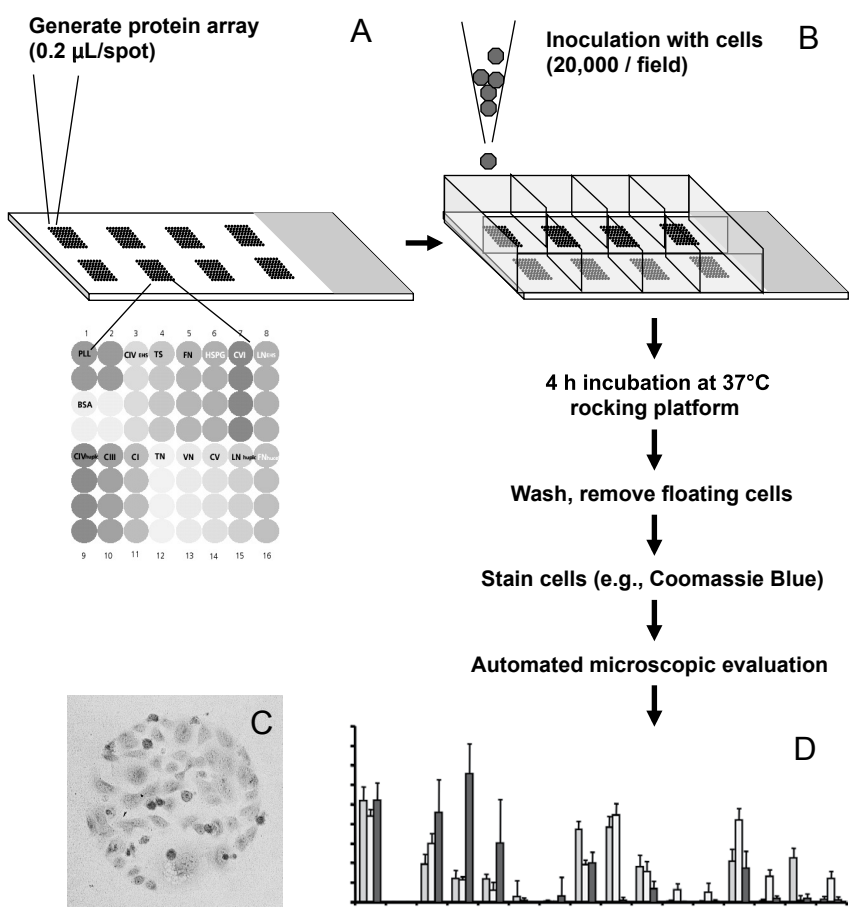

Figure 1: Investigation of cell binding to different proteins by adhesion screening on a multiple substrate array.

The basic concept of a multiple substrate array screen to investigate long-term interactions of cells on either different proteins, or on serial dilutions of a given protein, or combinations thereof, is outlined in a simplified graph. Protein arrays were generated by a micro blotter on NC-coated glass slides (A). Remaining NC was blocked by StabilGuard ${ }^{\circledR}$, and cell culture ch by a silicon frame. Cells were added in DMEM medium (B) and incubated as indicated. After removal of floating cells, cells binding to the spots on the array were stained (C) and counted by an automated process (D). Technical details can be found in the original work published recently [22]
In a second series of investigations, binding of MSC to the selected peptides was explored in the same way, as described for proteins. However, since some small peptides may be not be accessible to cells when applied directly to the NC-coated surface, the peptides were coupled to BSA, by aid of a maleimide-facilitated reaction (Figure 2). Briefly, BSA was functionalized with maleimide groups, as described [23]. Peptides acetylated at the N-terminal amino groups (NMI TT $\mathrm{GmbH}$, Reutlingen, Germany) were covalently attached to maleimide groups of the activated BSA (Cellendes $\mathrm{GmbH}$, Reutlingen, Germany), via the thiol-function of a $\mathrm{N}$-terminal cysteine residue. The peptides were used as crude trifluoro-acetic acid salts. The peptide-augmented BSA was spotted to the NC-coated glass slides, to generate the substrate array with peptides, as described [22]. The binding of the cells to the peptide-augmented BSA was enumerated, as described above. Binding of cells to PLL spots served as a positive control, while binding to unmodified BSA as a negative control.

\section{Cell attachment assay}

In a third line of experiments, the initiation of attachment of cells was investigated in more detail [24]. To this end, selected peptides were coupled to activated BSA, as described above (Figure 2), spotted to cell culture dishes (Figures $3 \mathrm{~A}$ and $3 \mathrm{~B}$ ), and air-dried. The remaining surface was sealed with naïve (i.e. chemically not modified) BSA and $5 \times 10^{5}$ cells/dish were allowed to initiate attachment for only a short time (15-20 min), without rocking the samples (Figure 3C). Floating cells were then removed by aspiration of the supernatants, and by vigorously rinsing the samples with PBS. For evaluation, the spots were recorded by phase contrast microscopy, with a digital camera device (Zeiss Axiovert 200M). In these experiments, naive BSA served as a negative control, and attachment to either laminin-111 or fibronectin served as a positive control (Figure 3D). For this type of cell-peptide interaction, the term "attachment" is used throughout this article. A cell attachment index was established to facilitate the comparison of the affinities of the peptides and cells included. The attachment index represents the number of different samples (i.e. MSC or fibroblast of a given donor), bound to a particular peptide, compared to all samples tested and expressed as \% of total samples bound.

\section{Statistics}

Cell binding and cell attachment data are presented as mean values ( \pm standard deviations) of multiple individual experiments. Statistical significance was tested by a double-sided student's T-test. P-values smaller than 0.5 were considered significant.

\section{Results}

\section{Binding of mesenchymal stromal cells to extracellular matrix proteins}

Binding of bmMSC to ECM proteins was investigated in comparison to SF. A strong binding of MSC and SF to PLL was evident, while only a few cells adhered to BSA (Figure 4). Both MSC and SF adhered well to fibronectin, either isolated from the extracellular matrix $\left(\mathrm{FN}_{\text {hupls }}\right)$, or from cellular sources $\left({ }_{\text {cellular }} \mathrm{FN}\right)$. Fibroblasts and MSC adhered to vitronectin and laminin-511. In contrast, weak or no binding was recorded for thrombospondin, heparan sulfate proteoglycan, and -with one exception in this experiment-for type V-collagen (Figure 4). Interestingly, no protein revealed a higher binding affinity to SF compared to MSC, but MSC attached more frequently, and/or more vividly to laminin-111, type IV-, III-, and I-collagens, and tenascin-C. To a lesser degree, this difference was also observed for binding of MSC 
Citation: Roncoroni LP, Maerz JK, Angres B, Steuer H, Benz K, et al. (2013) Adhesion to Extracellular Matrix Proteins can Differentiate between Human Bone Marrow Derived Mesenchymal Stem Cells and Fibroblasts. J Tissue Sci Eng S11: 008. doi:10.4172/2157-7552.S11-008

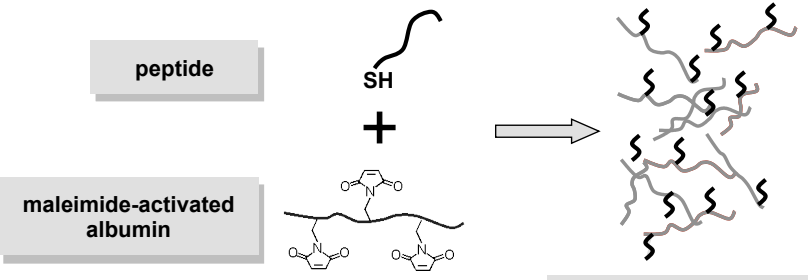

peptide-modified BSA

Figure 2: Covalent coupling of peptides to bovine serum albumin (BSA).

Peptides were synthesized with a short spacer and a free SH-group at the $\mathrm{N}$-terminus. BSA was activated by reaction of 3-(maleimido)-propionic acid $\mathrm{N}$-hydroxysuccinimde ester, attaching a maleimide group to the side chains of the lysins in BSA. The peptide was covalently coupled to BSA by nucleophilic addition of the $\mathrm{SH}$-group to the maleimide double bond (Michael reaction).
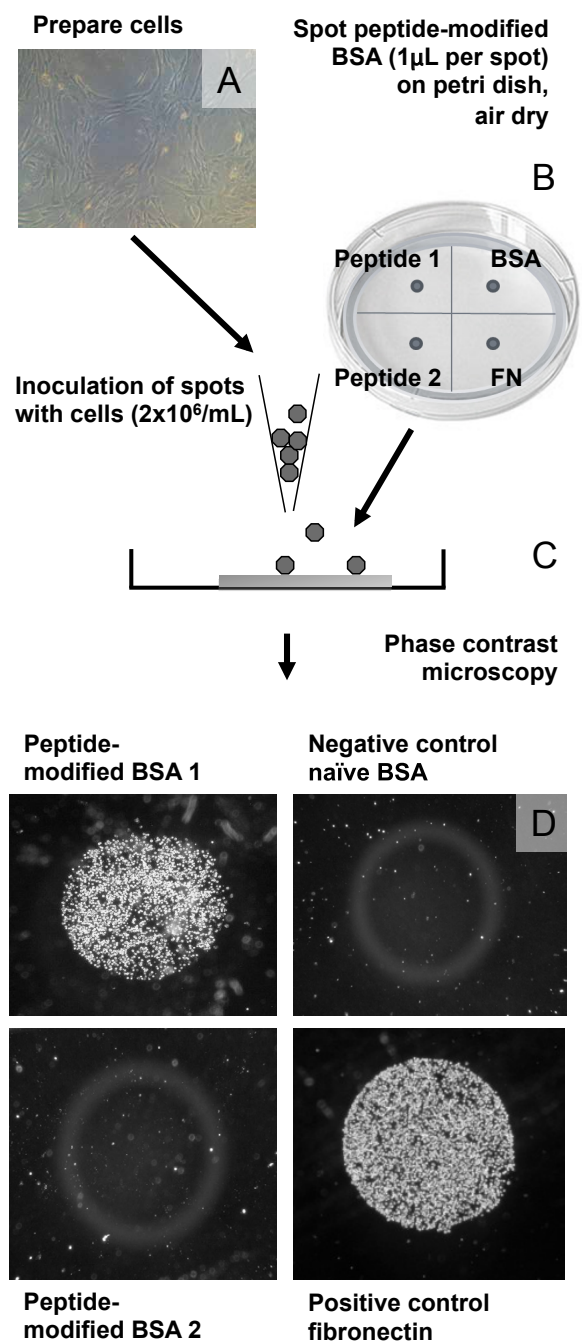

Figure 3: Short-term attachment assay.

Cells were prepared and resuspended in serum-free DMEM $\left(2.3 \times 10^{6} / \mathrm{mL} ; A\right)$ Peptide-modified BSA probes, naïve BSA or control proteins were spotted on a petri dish as indicated (B). After blocking the plastic surface with BSA, cells were added and incubated for $15-20 \mathrm{~min}$ in a humidified incubator $\left(37^{\circ} \mathrm{C}, 5 \%\right.$ $\mathrm{CO}_{2}$; C). Floating cells were aspirated, the samples were washed with PBS and attached cells were visualized by phase contrast microscopy. Technical details have been described recently [24]. versus SF to type IV-collagen, when isolated from supernatants of the murine EHS cell line (Coll $\left.\mathrm{IV}_{\mathrm{EHS}}\right)$, or from human placenta $\left(\mathrm{Coll}_{\mathrm{IV}} \mathrm{huplc}\right.$ Figure 4).

\section{Binding of mesenchymal stromal cells to matrix protein- derived peptides}

Based on the proteins which preferentially bound MSC (Figure 4), 57 peptides ( 4 to 29 amino acids long) were delineated to compare binding to MSC (Figures 5A and 5B), or fibroblasts (Figures $5 \mathrm{C}$ and $5 \mathrm{D})$ by $\mathrm{MSA}^{\circledR}$ techniques. In agreement with the total protein data, MSC bound to more individual peptides compared to fibroblasts, and the number of cells per spot was higher for several of these peptides with MSC, compared to the number of cells per spot observed with fibroblasts (Figure 5). Both cell types, MSC and fibroblasts bound to peptide $\mathrm{P} 11$, a control peptide containing the RGD binding motive (Figures 5A and 5C). MSC and fibroblasts bound to the lamininderived P16, as well (Figures 5A and 5C). A somewhat stronger binding of SF was recorded with the vitronectin-derived peptide P37, compared to MSC. In contrast, stronger binding of MSC to collagen-derived P5, fibronectin-derived peptides P21 and P22 was observed. The lamininderived peptides, P15 and P57, also showed better binding to MSC than fibroblasts. Therefore, the interaction of MSC with these peptides was investigated further in a short-term attachment assay.

\section{Initial attachment of MSC and fibroblasts to selected peptides}

Peptides P5, P15, P16 P21, P22 and P57 were further investigated for short-term cell-peptide interactions (Figure 6). Short-term attachment to laminin-111 and fibronectin served as positive controls, and attachment to BSA as a negative control. In this series of experiments, almost all MSC (87\%) attached to the laminin-derived peptide P16. Interestingly, MSC failed to demonstrate rapid attachment to peptides P5, P15, P22 or P57 (Figure 6). However, less than $70 \%$ of fibroblast samples attached to peptide P16. A small number of MSC attached to the fibronectin-derived peptides P21, and a third of the fibroblast samples investigated attached to P21 (Figure 6). Attachment of fibroblasts to P5, P15, P22 or P57 was not observed. This data demonstrates that human bone marrow derived MSC and fibroblasts differ in adhesion to extracellular matrix proteins and peptides, and it provides evidence that attachment of MSC or fibroblasts (i.e. short- term assays) differs from binding (i.e. long-term assay) of the these cells.

\section{Discussion}

Binding of MSC to some of the proteins investigated in this study clearly differs from binding of fibroblasts to the same substratum. We, therefore, hypothesized that these differences in binding could possibly be applied to define peptides, and/or epitopes involved in MSC-specific cell-matrix interactions. Integrins, of course, are important for cellmatrix interactions. MSC share the expression of different integrins chains, such as $\alpha 1-, \alpha 2-, \alpha 5-$ and $\beta 1$-chains, with other mesenchymal cells, including osteoblasts, chondrocytes or fibroblasts. However, differences between MSC and osteoblasts were seen for examples for the expression of a3-integrin [25,26]. Slightly different binding patterns to extracellular matrix components were also reported for type III collagen, which binds MSC efficiently (Figure 4), but not osteoblasts [26]. The binding patterns reported in our study for MSC to fibronectin, laminin and vitronectin (Figure 4) match the previous binding patterns reported for osteoblasts [26].

Comparably, chondrocytes express the $\alpha 5 \beta 1$-integrin and binding to fibronectin, type-VI collagen and vitronectin, was reported [27]. In addition, chondrocytes express $\alpha 1-$ and $\alpha 3$-chains at low levels, 
Citation: Roncoroni LP, Maerz JK, Angres B, Steuer H, Benz K, et al. (2013) Adhesion to Extracellular Matrix Proteins can Differentiate between Human Bone Marrow Derived Mesenchymal Stem Cells and Fibroblasts. J Tissue Sci Eng S11: 008. doi:10.4172/2157-7552.S11-008

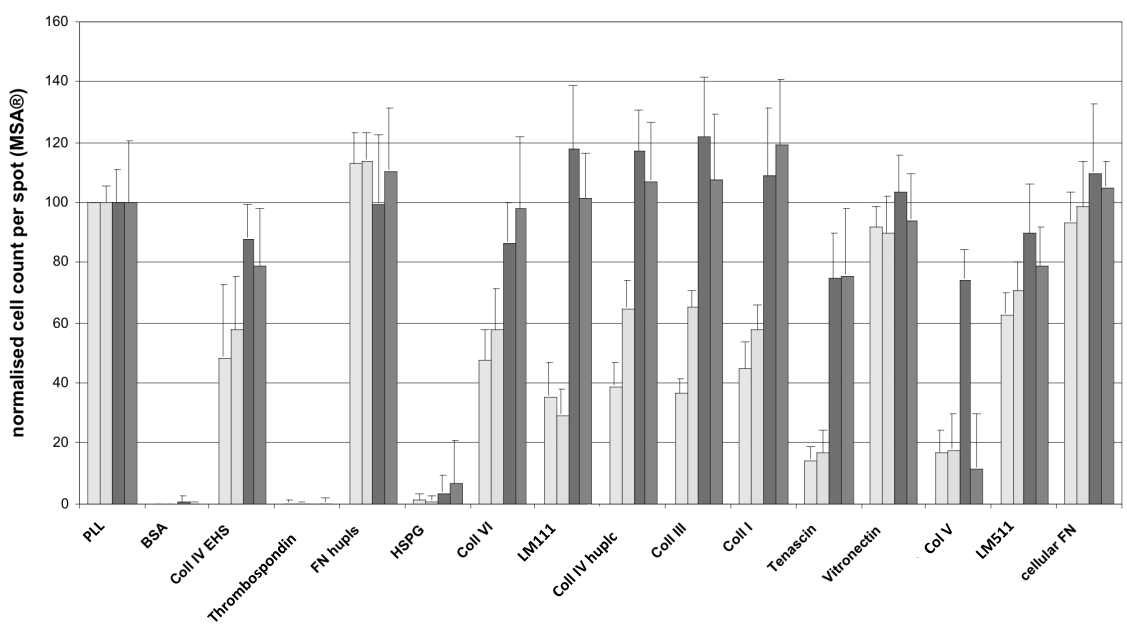

Figure 4: Comparing the long-term binding of MSC and fibroblasts to different proteins in $\mathrm{MSA}^{\circledR}$ assays.

Binding of MSCs ( $n=2$ donors, dark grey bars) or fibroblasts ( $n=2$ donors, light grey bars) to extracellular matrix proteins was explored as outlined in figure 1. Binding of the cells to poly-L-lysine (PLL) served as a positive control $(=100 \%)$, and binding to BSA as a negative control (=0\%). Binding to (from left to right) murine type IV collagen (EHS), thrombospondin, fibronectin (from human placenta), heparan sulfate proteoglycan (HSPG), human type VI collagen (from human placenta), laminin-111 (LM111), type VI collagen, type III collagen, type I collagen, tenascin-C, vitronectin, human type $V$ collagen, laminin-511 (LM511), and cellular fibronectin was measured. MSC bound stronger to laminin-111, type-I-, type-III-, and type-IV-collagens, whereas for other proteins (e.g. fibronectin (FN), vitronectin, laminin-511), no difference was measured.
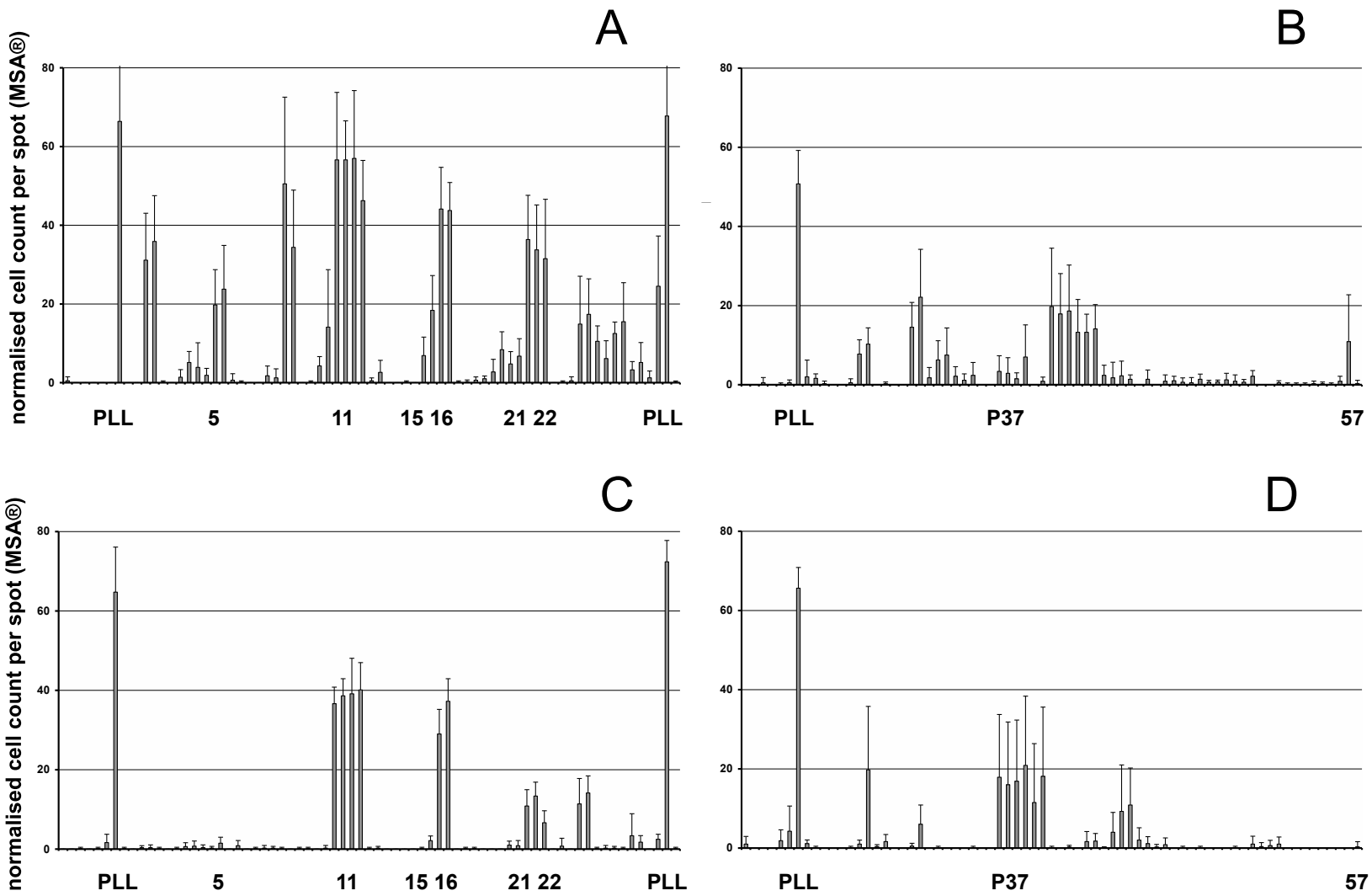

Figure 5: Comparing the long-term binding of MSC and fibroblasts to different peptides by MSA ${ }^{\circledR}$

Binding of MSC (panels $A, B$ ) or fibroblasts (panels $C, D$ ) to peptides attached to BSA was explored, as outlined in figure 1. Binding of the cells to poly-L-lysine (PLL) served as a positive contro, I and binding to unmodified BSA as a negative control. The binding patterns generated with relevant peptides $(5,11,15,12,21,22,37,57)$ are marked. The ordinate presents the normalized numbers of cells binding per spot on a scale from 0 to 80 . 


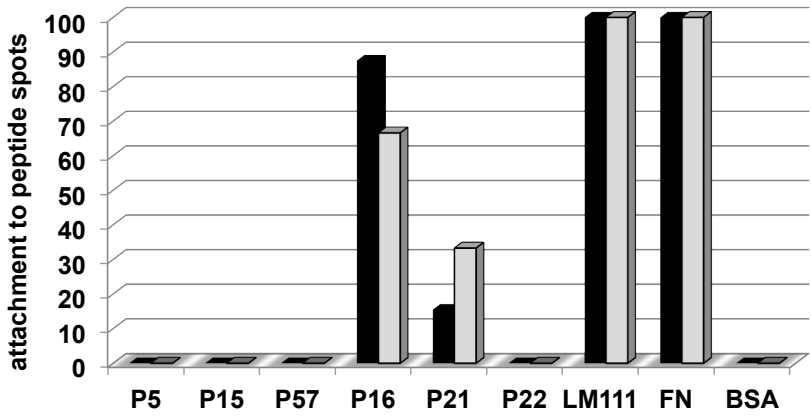

Figure 6: Exploring the short-term attachment of MSC and fibroblasts to distinct peptides.

Short-term attachment of MSC (black bars) and fibroblasts (grey bars) to selected peptides was investigated, as described in figure 3. Attachment of the cells to laminin-111 (LM111) or fibronectin (FN) served as positive controls, and attachment to BSA as a negative control. The ordinate presents the cel attachment index. This is the number of samples bound to a particular peptide compared to all samples tested, and expressed as \% of total samples bound.

and not on all populations, and failed to express other $\alpha$-chains, or the $\beta 3$-integrin [28]. In contrast, human fibroblasts express the $\alpha 1 \beta 1$ integrin at high levels, but fail to express the $\alpha 2$-chain in vitro, at levels required for a measurable matrix interaction, without stimulation [29,30]. Moreover, expression of the collagen-binding integrin a11chain was significantly higher on MSC, compared to fibroblasts [31]. Due to the differences in expression of integrins between MSC and other mesenchymal cells, it seems feasible to search for substrates that preferentially bind MSC. In addition, MSC from different sources, such as bone marrow or placenta, may differ in their expression of integrins. Our preliminary data on the transcript level would support this notion. However, this must be confirmed on the protein level. Patterns of expression of matrix proteins were not in the focus of this present study.

The proteins in the current study which yielded different binding patterns for MSC and fibroblasts were laminin-111, the type-I, -III, -IV, and -VI collagens and tenascin-C. These proteins share in terms of substrate binding to integrins [32]. For collagen binding, the a1-, $\alpha 2-, \alpha 10-$, and $\alpha 11$-integrin chains combine with the $\beta 1$-integrin, while binding of laminins requires that the $\alpha 1-, \alpha 2-, \alpha 3-, \alpha 6-$, and $\alpha 7$-integrin chains combine with $\beta 1$-integrin. For binding to tenascin- $C$, the $\alpha 2 \beta 1$ receptor was described $[32,33]$. We recently confirmed that human MSC express most of the above listed integrins ( $\alpha 1, \alpha 2, \alpha 3, \alpha 6, \alpha 7, \alpha 9$, a11, $\beta 1$ ) [16], required for strong binding to collagens, laminin-111 and tenascin-C. Moreover, TGF- $\beta 1$ induced an elevated expression of the $\alpha 2-, \alpha 6-$, and $\beta 1$-integrins, thus, further facilitating binding of MSC to the ECM components listed above [16].

Human fibroblasts express little $\alpha 2 \beta 1$-integrin in vitro, unless inoculated on collagen-coated cell culture dishes [29]. This indicates that expression of integrins is regulated by extracellular matrixto-cell signaling. Moreover, as observed with MSC [16], TGF- $\beta 1$ induced elevated expression of $\alpha 2 \beta 1$-integrin in fibroblasts, as well [30]. Therefore, cytokines regulate the expression of integrins too. But in our experiments, cells were not grown in collagen-coated dishes, nor were TGF- $\beta 1$ added to the cell culture media. MSC and fibroblasts were expanded in medium containing $10 \%$ FCS. Therefore, TGF- $\beta 1$, naturally occurring in bovine sera, may influence the integrin expression on MSC and other cells, unintentionally. In addition, MSC express TGF- $\beta 1$ in vitro (our own unpublished results and [34]). We, therefore, cannot exclude that TGF- $\beta 1$ may have up-regulated the expression of $\alpha 2 \beta 1$ - or $\alpha \beta 1$-integrins in an autocrine manner in our experiments, and may have, therefore, influenced our results. The TGF$\beta 1$-dependent expression of $\alpha 2 \beta 1$-, $\alpha 6 \beta 1$-, or $\alpha 11 \beta 1$-integrins on MSC might be a critical factor for compensating differences in substrate binding observed between MSC and fibroblasts.

In long-term cell binding arrays, more than $80 \%$ of MSC samples displayed strong binding to peptide P16 (Figure 5A), whereas less than $70 \%$ of the fibroblasts bound to this peptide (Figure 5C). The same pattern was observed in a short-term attachment assay (Figure 6). In contrast to P16, fibroblasts yielded a somewhat higher affinity to peptide P21 in the short-term attachment assay (incubation for $15 \mathrm{~min}$, Figure 3), compared to MSC (Figure 6), whereas MSC yielded a stronger binding to peptide P21 in the long-term attachment assay (Figure 5). These differences may only reflect variables due to the technical differences applied, when studying binding versus attachment. However, it may also indicate that the initial contact of a cell to the binding epitope and short-term interactions (i.e., the "on-rate"), follows different kinetics compared to the "off-rate". In addition, cooperative effects between several binding sites of either a given integrin to a given peptide motive, or cooperative effects between different integrins sharing the affinity to that peptide, may account for the differences recorded.

At any rate, peptides 16 and P21 served as substratum for MSC and fibroblasts in the attachment assay, and in the binding array, and this was at least in part in agreement with binding of these cells the total protein. In contrast, the collagen IV-and the laminin- $\alpha$-chain-derived peptides P5, 15, and P57, respectively, facilitated a measurable binding of MSC (Figure 5), but failed to enable a short-term attachment of MSC (Figure 6).

We conclude that the cell binding patterns, as determined by the $\mathrm{MSA}^{\circledR}$ method, result in considerably different substrate affinities, compared to the patterns determined by a short-term attachment assay. We show that the MSA ${ }^{\circledR}$ can address biocompatibility and inoculation characteristic of biomaterials intended for in vitro seeding of MSC, and for in vitro tissue engineering purposes. In contrast, the attachment assay can yield knowledge regarding the on- and off- rates of MSC to individual binding sites. This technique, therefore, complements the MSA ${ }^{\circledR}$, and may enable the selection of biomaterials intended for capturing MSC in situ during wound healing processes. Biomaterials containing the peptide P16 motive may be a compromise serving both purposes. But based on current data, we cannot conclusively postulate that all the peptides presented in this study, which preferentially bind to expanded MSC in vitro, will be suitable for clinical applications in situ, as binding of these peptides to MSC must be confirmed with cells ex vivo. And a clear specificity of preferred MSC attachment or MSC binding over interactions with fibroblasts was not resolved in this first study. Again, this must be investigated in future experiments in an ex vivo or in vivo context, as well. Moreover, additional peptides have to be screened to eventually define a MSC-specific attachment, and or binding motive.

\section{Acknowledgements}

This project was supported by a grant from the Baden-Württemberg Stiftung (MatriXELECT project), in part by grants from BMBF and DFG, and by institutional funding. The authors thank Mrs. Stephanie Zug and Elisabeth Kienzle, for their excellent technical support, and Chaim Goziga, for help in preparation of the artwork. 
Citation: Roncoroni LP, Maerz JK, Angres B, Steuer H, Benz K, et al. (2013) Adhesion to Extracellular Matrix Proteins can Differentiate between Human Bone Marrow Derived Mesenchymal Stem Cells and Fibroblasts. J Tissue Sci Eng S11: 008. doi:10.4172/2157-7552.S11-008

\section{References}

1. De Bari C, Dell'Accio F, Tylzanowski P, Luyten FP (2001) Multipotent mesenchymal stem cells from adult human synovial membrane. Arthritis Rheum 44: 1928-1942.

2. Parolini O, Alviano F, Bagnara GP, Bilic G, Bühring HJ, et al. (2008) Concise review: isolation and characterization of cells from human term placenta: outcome of the first international Workshop on Placenta Derived Stem Cells. Stem Cells 26: 300-311.

3. Pittenger MF, Mackay AM, Beck SC, Jaiswal RK, Douglas R, et al. (1999) Multilineage potential of adult human mesenchymal stem cells. Science 284 : 143-147.

4. Fukuchi Y, Nakajima H, Sugiyama D, Hirose I, Kitamura T, et al. (2004) Human placenta-derived cells have mesenchymal stem/progenitor cell potential. Stem Cells 22: 649-658.

5. Zannettino AC, Paton S, Arthur A, Khor F, Itescu S, et al. (2008) Multipotential human adipose-derived stromal stem cells exhibit a perivascular phenotype in vitro and in vivo. J Cell Physiol 214: 413-421.

6. Friedenstein AJ, Chailakhyan RK, Gerasimov UV (1987) Bone marrow osteogenic stem cells: in vitro cultivation and transplantation in diffusion chambers. Cell Tissue Kinet 20: 263-272.

7. Harichandan A, Bühring $\mathrm{HJ}$ (2011) Prospective isolation of human MSC. Best Pract Res Clin Haematol 24: 25-36.

8. Barry FP, Murphy JM (2004) Mesenchymal stem cells: clinical applications and biological characterization. Int J Biochem Cell Biol 36: 568-584.

9. Le Blanc K, Ringdén O (2006) Mesenchymal stem cells: properties and role in clinical bone marrow transplantation. Curr Opin Immunol 18: 586-591.

10. Parolini O, Alviano F, Bergwerf I, Boraschi D, De Bari C, et al. (2010) Toward cell therapy using placenta-derived cells: disease mechanisms, cell biology, preclinical studies, and regulatory aspects at the round table. Stem Cells Dev 19: 143-154.

11. Aicher WK, Bühring HJ, Hart M, Rolauffs B, Badke A, et al. (2011) Regeneration of cartilage and bone by defined subsets of mesenchymal stromal cells-potential and pitfalls. Adv Drug Deliv Rev 63: 342-351.

12. Vogel W, Grünebach F, Messam CA, Kanz L, Brugger W, et al. (2003) Heterogeneity among human bone marrow-derived mesenchymal stem cells and neural progenitor cells. Haematologica 88: 126-133.

13. Bühring HJ, Battula VL, Treml S, Schewe B, Kanz L, et al. (2007) Novel markers for the prospective isolation of human MSC. Ann N Y Acad Sci 1106: 262-271.

14. Bühring HJ, Treml S, Cerabona F, de Zwart P, Kanz L, et al. (2009) Phenotypic characterization of distinct human bone marrow-derived MSC subsets. Ann N Y Acad Sci 1176: 124-134.

15. Battula VL, Treml S, Bareiss PM, Gieseke F, Roelofs H, et al. (2009) Isolation of functionally distinct mesenchymal stem cell subsets using antibodies agains CD56, CD271, and mesenchymal stem cell antigen-1. Haematologica 94: 173184

16. Warstat K, Meckbach D, Weis-Klemm M, Hack A, Klein G, et al. (2010) TGFbeta enhances the integrin alpha2beta1-mediated attachment of mesenchymal stem cells to type I collagen. Stem Cells Dev 19: 645-656.

17. Gregor AP, Christine U, Manuel R, Harald A, Richard S, et al. (2011) Human term placenta-derived mesenchymal stromal cells are less prone to osteogenic differentiation than bone marrow-derived mesenchymal stromal cells. Stem Cells Dev 20: 635-646.

18. Haas C, Aicher WK, Dinkel A, Peter HH, Eibel H (1997) Characterization of SV40T antigen immortalized human synovial fibroblasts: maintained expression patterns of EGR-1, HLA-DR and some surface receptors. Rheumatol Int 16 241-247.
19. Alexander D, Judex M, Meyringer R, Weis-Klemm M, Gay S, et al. (2002) Transcription factor Egr-1 activates collagen expression in immortalized fibroblasts or fibrosarcoma cells. Biol Chem 383: 1845-1853.

20. Dominici M, Le Blanc K, Mueller I, Slaper-Cortenbach I, Marini F, et al. (2006) Minimal criteria for defining multipotent mesenchymal stromal cells. The International Society for Cellular Therapy position statement. Cytotherapy 8 315-317.

21. Felka T, Schäfer R, De Zwart P, Aicher WK (2010) Animal serum-free expansion and differentiation of human mesenchymal stromal cells. Cytotherapy 12: 143 153

22. Kuschel C, Steuer H, Maurer AN, Kanzok B, Stoop R, et al. (2006) Cell adhesion profiling using extracellular matrix protein microarrays. Biotechniques 40: $523-531$.

23. Benz K, Freudigmann C, Müller J, Wurst H, Albrecht D, et al. (2010) A polyethylene glycol-crosslinked serum albumin/hyaluronan hydrogel for the cultivation of chondrogenic cell types. Adv Eng Mater 12: B539-B551.

24. Klein G (1995) The extracellular matrix of the hematopoietic microenvironment Experientia 51: 914-926.

25. Majumdar MK, Keane-Moore M, Buyaner D, Hardy WB, Moorman MA, et al (2003) Characterization and functionality of cell surface molecules on human mesenchymal stem cells. J Biomed Sci 10: 228-241.

26. Gronthos S, Stewart K, Graves SE, Hay S, Simmons PJ (1997) Integrin expression and function on human osteoblast-like cells. J Bone Miner Res 12 1189-1197.

27. Loeser RF (1993) Integrin-mediated attachment of articular chondrocytes to extracellular matrix proteins. Arthritis Rheum 36: 1103-1110.

28. Salter DM, Hughes DE, Simpson R, Gardner DL (1992) Integrin expression by human articular chondrocytes. Br J Rheumatol 31: 231-234

29. Ehrlich HP, Cremona O, Gabbiani G (1998) The expression of alpha 2 beta integrin and alpha smooth muscle actin in fibroblasts grown on collagen. Cell Biochem Funct 16: 129-137.

30. Arora PD, Narani N, McCulloch CA (1999) The compliance of collagen gels regulates transforming growth factor-beta induction of alpha-smooth muscle actin in fibroblasts. Am J Pathol 154: 871-882.

31. Halfon S, Abramov N, Grinblat B, Ginis I (2011) Markers distinguishing mesenchymal stem cells from fibroblasts are downregulated with passaging Stem Cells Dev 20: 53-66.

32. Ivaska J, Heino J (2000) Adhesion receptors and cell invasion: mechanisms of integrin-guided degradation of extracellular matrix. Cell Mol Life Sci 57: 16-24.

33. Srichai MB, Zent R (2010) Integrin structure and function. In: Cell-extracellular matrix interactions in cancer. Springer 19-41.

34. Salazar KD, Lankford SM, Brody AR (2009) Mesenchymal stem cells produce Wht isoforms and TGF-beta1 that mediate proliferation and procollagen expression by lung fibroblasts. Am J Physiol Lung Cell Mol Physiol 297 L1002-L1011. 